SciDioc

International Journal of Dentistry and Oral Science (IJDOS)

ISSN: 2377-8075

\title{
Evaluation Of Linear Dimensional Stability of BD Impress And Nexus Medodent Thermoplastic Impression Materials" - An In Vitro Comparative Study
}

Research Article

Arun Thomas Philip ${ }^{1 *}$, Kalavathi.S.D ${ }^{2}$, Naveen.B.H ${ }^{3}$, Ajay Balaji ${ }^{4}$

${ }^{1}$ Post Graduate Student, Department of Prosthodontics, Sri Siddhartha Dental college, Agalakote, Tumkur- 572107 Karnataka, India.

${ }^{2}$ Reader, Department of Prosthodontics, Sri Siddhartha Dental college, Agalakote, Tumkur- 572107, Karnataka, India.

${ }^{3}$ Professor and head, Department of Prosthodontics, Sri Siddhartha Dental college, Agalakote, Tumkur- 572107, Karnataka, India.

${ }^{4}$ Post Graduate Student, Department of Prosthodontics, Sri Siddhartha Dental college, Agalakote, Tumkur- 572107, Karnataka, India.

\section{Abstract}

\begin{abstract}
Aim: To evaluate and compare the linear dimensional stability of two commercially available BD IMPRESS and NEXUS MEDODENT thermoplastic impression materials.

Methodology: A total of 90 samples in which 45 samples of BD Impress and Nexus medodentimpession materials were used for evaluation of linear dimensional stability of these newly introduced thermoplastic impression materials. The samples were first checked under toolmaker microscope for reproduction of three parallel lines x,y,z. The measurements were made on the samples at 0 (within 24 hours), 7th and 14th day respectively to assess the linear dimensional stability.

Result: According to the study conducted and results obtained, it was concluded that NEXUS MEDODENT was superior in linear dimensional stability on comparison with BD IMPRESS impression material

Conclusion: On comparison with BD impress, nexus medodent impression material was superior in terms of linear dimensional stability. There is a need for further studies to know about other properties of these thermoplastic impression materials to enhance knowledge and for clinical application as indicated by manufacturers.
\end{abstract}

Keywords: Linear Dimensional Stability; Nexus Medodent; BD Impress; Thermoplastic Impression Materials.

\section{Introduction}

As the adage goes "Love at first sight", for dentist and prosthodontist "Impression is the pivotal point for a lasting relationship between the dentist and a patient". Hence a good impression material with an appropriate technique will provide the dentist a lasting impression or an excellent prosthesis amicable to both dentist and the patient.

An impression is defined as a negative likeness or copy in reverse of the surface of an object; an imprint of the teeth and adjacent structures for use in dentistry (GPT-9). Any substance or combination of substances used for making an impression or negative reproduction is called as an impression material. Impression materials have a number of properties that contribute to clinical success. [1] Impression materials are used to register or reproduce the form and relations of the teeth and surrounding oral tissues. [2] Dimensional stability is a desirable physical property of dental impression materials, which is defined as ability of a material to retain its size and form. [3] The success of dental prosthesis depends upon the accuracy with which it can be procured in the dental laboratory, using models obtained from the impressions. The accuracy and functional efficiency of the prosthesis depend upon how well the model replicates the natural oral tissues, which in turn depends on the accuracy and linear dimensional stability of the impression in which it was poured. A number of factors contribute to the accuracy or linear dimensional stability of the impression including the ability to flow on contact with the oral tissues during seating of the impression and an ability of the fluid material to contact the moist surfaces intimately in order to record the details and avoid air inclusions. The ideal requirements of an impression material include factors which affect the accuracy and linear dimensional stability of the impression, setting character-

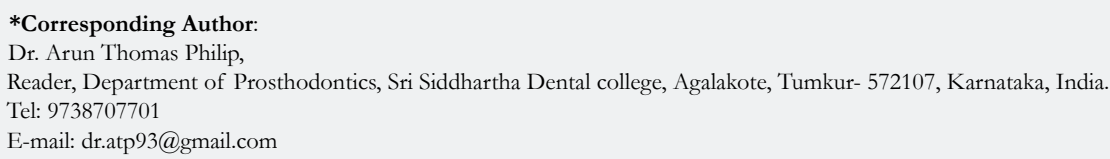

Copyright: Dr. Arun Thomas Philip ${ }^{\complement} 2021$. This is an open-access article distributed under the terms of the Creative Commons Attribution License, which permits unrestricted use, distribution and reproduction in any medium, provided the original author and source are credited. 
istics, ease of handling, cost of the material and so on. Among these, linear dimensional stability and accuracy of the impression are considered to be the most important factors as they directly affect the outcome of the fabrication of the prosthesis. The dimensional changes of the impression materials may affect the quality of fit and retention of dental prostheses, which influences the success of indirect restorative treatment. The linear dimensional stability of impression material is influenced by humidity, the time interval from mixing to loading on the impression tray and the thickness of the layer of material in the impression tray, to name a few.[4]

Among the impression materials available, elastomeric impression materials such as polyvinylsiloxane, polyether are most popular because of their excellent detail reproduction and good linear dimensional stability. Although polyether and vinyl polysiloxane (VPS) materials are chemically distinct, they have similar physical characteristics when set, in which many of these properties render the impression materials clinically useful. Numerous studies have indicated differing properties among and within elastomeric groups. For example, two recent studies have shown that polyethers exhibit useful clinical properties. One investigation into the viscoelastic behaviour of impression materials in a gingival sulcus simulation model reported that polyether reproduce the greatest sulcular extension, suggesting a direct clinical benefit. In another study, under moist surface conditions, better detail reproduction was reproduced by polyether than most VPS materials. Such information provides the practitioner the information to judiciously select the material possessing properties that best suit the needs of the procedure being undertaken.[2]

Because of their exceptional linear dimensional stability, few practitioners send unpoured impressions to distant commercial dental laboratories for fabrication or pour the impressions at differed times. While the impressions are being sent to laboratories, they may be subjected to various temperature changes in transit. The factors that result in dimensional changes are temperature, humidity, and polymerization shrinkage and so on.[4]

While considering the linear dimensional stability of various elastomeric impression materials, literature and information are readily available, but little or no information is available on the properties of BD Impress and Nexus Medodent thermoplastic impression materials, as they are new entrants in the market. Therefore efforts are made to know about one of the physical property namely, the linear dimensional stability of BD Impress(Merz Dental) and Nexus Medodent (NMD), the newly introduced thermoplastic impression materials.

The purpose of this study is to evaluate and compare thelinear dimensional stability of two recent thermoplastic impression materials BD Impress and Nexus Medodent.

\section{Methodology}

A stainless steel mold was made according to ADA specification no.19 with parts, containing a ruled block, outer ring, and a riser. (Fig-1)

The standard stainless steel mold with ADA specification no.19 was prepared with parts, containing a ruled block, outer ring, and a riser. The measurements of stainless steel mold are as follows-The total height is $37 \mathrm{~mm}$ with a diameter of $38 \mathrm{~mm}$. A ruled block with a diameter of $30 \mathrm{~mm}$, thickness of $3 \mathrm{~mm}$, ingrained with 3 horizontal lines $\mathrm{x}, \mathrm{y}, \mathrm{z}$ with width $50 \pm 8 \mu \mathrm{m}, 20 \pm 4 \mu \mathrm{m}, 75 \pm 8 \mu \mathrm{m}$ respectively, and 2 vertical lines $\mathrm{c}$ and $\mathrm{d}$ with width $75 \pm 8 \mu \mathrm{m}$.(Fig2) All lines intersecting at $90^{\circ}$ angle.(Fig-2)

An outer ring with the inner diameter of $30 \mathrm{~mm}$ and outer diameter of $38 \mathrm{~mm}$ and height of $6 \mathrm{~mm}$. The riser with a diameter of $30 \mathrm{~mm}$ and height of $3 \mathrm{~mm} .5$

\section{Preparation Of Samples}

The BD impress (fig.3a) and NEXUS medodent(fig.3b) impression materials were used for preparation of samples for comparison of linear linear dimensional stability between the two. The BD impress impression material was dispensed and kept ready for manipulation. The impression material is small in size, spherical in shape and is available as white colored pellets. The prepared stainless steel mold was cleaned using ultrasonic cleanerusing distilled water to remove any residues of impression materials. Care should be taken to protect the surface of the mold to avoid any contamination. A light coat of petroleum jelly was applied using gauze to facilitate removal of the ring from the mold. Hot water about $65^{\circ}-80^{\circ} \mathrm{C}$ should be maintained in a temperature controlled water bath which is to be used for manipulation of the thermoplastic impression material. The impression material was placed in hot water and was allowed to soften. The impression material became transparent, as it reached the softening temperature, fuses and forms a gel like consistency, which has to be properlykneaded to make it a homogeneous mixture.

After proper manipulation of the material, it was placed on the stainless steel mold, in such a way that it flows completely over the mold (Fig-4).A flat glass plate was placed over the mold such that pressure was applied over the impression material, firmly against the mold assuring a positive contact between the mold and impression material. A weight of $1 \mathrm{~kg}$ was placed over the glass plate for constant pressure (fig.5).This weight helped to create constant pressure that allowed the material to flow completely. The whole assembly was then transferred to the water which was kept at $35^{\circ} \mathrm{C} \pm 1$ simulating the mouth temperature. The material was allowed to set according to manufacturers recommended time.The excess material that leached out during compression setting, was removed by using a Bard Parker blade no.15,without disturbing the surface of the sample to be tested, the weight was removed followed by the sample.

The nexus medodent impression material was also manipulatedby the same procedure and samples were prepared.

\section{Evaluation Of Linear Linear Dimensional Stabil- ity}

After the samples were prepared, toolmaker microscope (30x magnification) was used to assess whether the 3 lines has been reproduced in the impression or not. Those impressions in which the 3 lines has been reproduced perfectly without any discontinuity was selected for assessing the linear linear dimensional stability. To assess the linear dimensional stability, line $\mathrm{Z}$ of the samples was measured between $\mathrm{D}$ and $\mathrm{D}^{\prime}$ immediately following the fabri- 
cation (within 24 hours). The samples were stored on table top at room temperature. The measurements were made on the samples at 0 (within 24 hours), 7 th and 14 th day respectively.

\section{Result}

45 samples of each impression material totaling of 90 samples, were viewed under toolmaker microscope at 0,7 th and 14th day respectively. The data collected was entered in Microsoft Excel and statistical analysis was performed using the IBM:SPSS (stastical package for social sciences) software. Significance among the means of two impression materials was done by ANOVA, commonly known as F-test. P-values of 0.05 at 95\% (confidence level) was used for significance of comparison between each material as significant, highly significant, very highly significant respectively. (Table-1)

According to the values obtained, the mean \pm standard deviation of each impression material has been compared at different intervals as following:

1. 0 day when compared with 7 th day for BD IMPRESS was $2.92644 \pm 0.0444$

2. 0 day when compared with 14 th day was $9.91667 \pm 0.0444$,

3. 7 th day when compared with 14 th day was $6.99022 \pm 0.0444$.

On the other hand the mean \pm standard deviation of Nexus medodent impression material was also compared at different intervals as:

Figure 1. ADA specification no.19 mold.

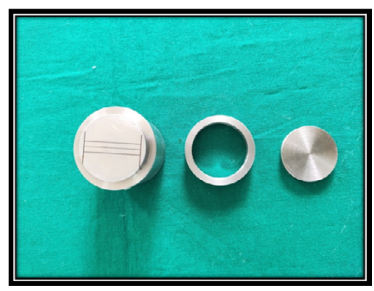

Figure 2. Schematic diagram of stainless steel mold ADA specification no.19.

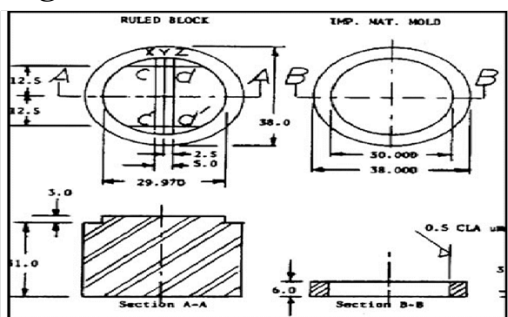

Figure 3A \& 3B. BD Impress and Nexus medodent thermoplastic impression materials.
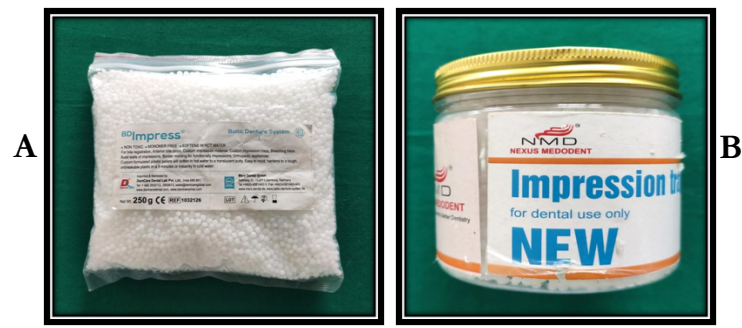

Figure 4. Impression material placed over the mold after manipulation.

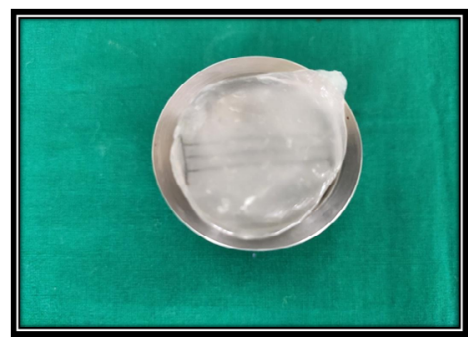

Figure 5. A weight of $1 \mathrm{~kg}$ placed over glass slab for constant pressure.

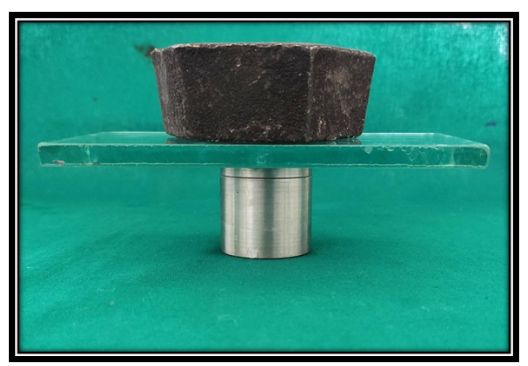


Table 1. Comparison for mean and standard deviation of linear dimensional stability for two thermoplastic impression materials at 0,7 th and 14 th day using ANOVA.

\begin{tabular}{|c|c|c|c|c|c|}
\hline & & Mean & Standard deviation & $\mathbf{F}$ & Significance \\
\hline \multirow{3}{*}{ BD Impress } & 0 day & 24.803 & 0.232 & \multirow{3}{*}{26333.45} & \multirow{3}{*}{0.000 (H.S) } \\
\hline & 7 th day & 21.876 & 0.203 & & \\
\hline & 14th day & 14.886 & 0.195 & & \\
\hline \multirow{3}{*}{ Nexus Medodent } & 0 day & 24.966 & 0.019 & \multirow{3}{*}{17873.074} & \multirow{3}{*}{0.000 (H.S) } \\
\hline & 7 th day & 24.879 & 0.036 & & \\
\hline & 14th day & 21.793 & 0.152 & & \\
\hline
\end{tabular}

Table 2. Comparison Of Each Impression Material At Different Time Intervals.

\begin{tabular}{|c|c|c|c|c|c|c|c|}
\hline & & & \multirow{2}{*}{$\begin{array}{l}\text { Mean dif- } \\
\text { ference }\end{array}$} & \multirow{2}{*}{$\begin{array}{c}\text { Standard } \\
\text { error }\end{array}$} & \multirow{2}{*}{$\begin{array}{l}\text { Signifi- } \\
\text { cance }\end{array}$} & \multicolumn{2}{|c|}{$95 \%$ Confidence Interval } \\
\hline & & & & & & Lower bound & Upper bound \\
\hline \multirow{3}{*}{$\begin{array}{c}\text { BD } \\
\text { Impress }\end{array}$} & \multirow{2}{*}{0 day } & 7th day & 2.926 & 0.044 & .000 (H.S) & 2.821 & 3.032 \\
\hline & & 14th day & 9.917 & 0.044 & .000 (H.S) & 9.811 & 10.022 \\
\hline & 7th day & 14th day & 6.990 & 0.044 & .000 (H.S) & 6.885 & 7.096 \\
\hline \multirow{3}{*}{$\begin{array}{c}\text { Nexus } \\
\text { Medodent }\end{array}$} & \multirow{2}{*}{0 day } & 7th day & 0.087 & 0.019 & .000 (H.S) & 0.042 & 0.132 \\
\hline & & 14th day & 3.173 & 0.019 & .000 (H.S) & 3.128 & 3.219 \\
\hline & 7 th day & 14th day & 3.086 & 0.019 & .000 (H.S) & 3.041 & 3.132 \\
\hline
\end{tabular}

Graph 1. Bar chart showing the amount of dimensional change of each impression material at 0,7 th and 14 th day.

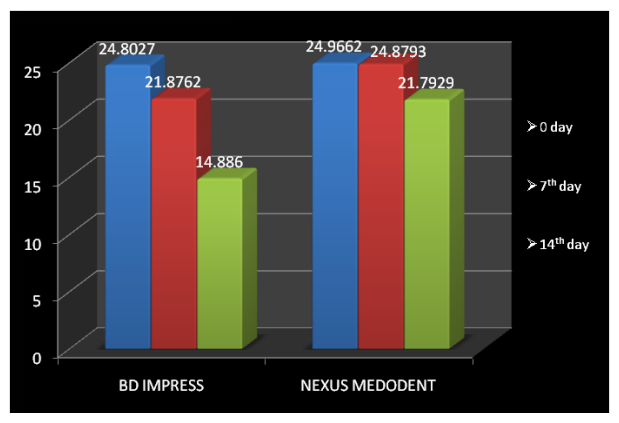

1. 0 day when compared with 7 th day was $0.8689 \pm 0.01912$

2. 0 day when compared with 14 th day was $3.17333 \pm 0.01912$

3. 7 th day when compared with 14 th day was 3.08644 \pm 0.01912 .

(Table-2)

A highly significant pattern was observed for both of the impression material. From the above mentioned results, it was concluded that NEXUS MEDODENT material showed least dimensional change when compared to BD IMPRESS.

\section{Discussion}

Impression making is the primary step in the process of fabrication of an indirect prosthetic restoration. Precision of the impression material in terms of linear dimensional stability, surface detail reproduction, and compatibility with gypsum products is an essential prerequisite for a successful restoration. [6] An impression is defined as a negative likeness or copy in reverse of the surface of an object; an imprint of the teeth and adjacent structures for use in dentistry. Any substance or combination of substances used for making an impression or negative reproduction is called as an impression material. Impression materials have a number of properties that contribute to clinical success.[1] Impression materials are used to register or reproduce the form and relations of the teeth and surrounding oral tissues.[2]

Linear dimensional stability is a desirable physical property of dental impression materials, which is defined as ability of a mate- rial to retain its size and form.[3] The accuracy and functional efficiency of the prosthesis depend upon how well the model replicates the natural oral tissues, which in turn depends on the accuracy and linear dimensional stability of the impression in which it was poured. A number of factors contribute to the accuracy or linear dimensional stability of the impression including the ability to flow on contact with the oral tissues during seating of the impression and an ability of the fluid material to contact the moist surfaces intimately in order to record the details and avoid air inclusions.

The common method for testing linear dimensional stability is by the use of ADA/ANSI specification no.19, an impression mold which helps to make the comparisons easier between different studies. [1, 4, 7, 8, 12, 15] The same mold has been used in the present study. This standard mold produces an impression specimen which allows only $2 \mathrm{D}$ measurement to assess the linear dimensional stability and surface detail reproduction of the impression specimens and hence it does not mimic clinical conditions which includes the use of trays, adhesives for making impressions and gypsum for making casts.[8]

The aim of this study done by William Thomas et al was to assess the effect of storage time and temperature on the linear dimensional stability of polyvinyl siloxane and polyether impression material. The results showed that the polyvinyl siloxane and polyether impression materials statistically significant dimensional changes at $10^{\circ} \mathrm{C}, 180^{\circ} \mathrm{C}, 350^{\circ} \mathrm{C}$, and $450^{\circ} \mathrm{C}$, whereas at $280^{\circ} \mathrm{C}$, all the tested materials showed no significant changes. Most of the 
changes occurred within 24 hours, with very little changes occurring in 48 and 72 hours. [4] Present study intended to investigate the linear dimensional stability at room temperature on table top with the newly introduced impression materials BD IMPRESS and NEXUS MEDODENT.

Shillingburg et al stated that polyvinyl siloxane impression materials are extremely precise when used in clinical dental practice. [9] The linear dimensional stability of a material was typically time reliant; Dentists have been reported to delay pouring of impressions up to 72 hours; therefore, it is important that an impression material should remain dimensionally accurate for this stage of time. Polyvinyl siloxane impression materials have demonstrated finer linear dimensional stability when evaluated with other elastomeric materials, principally because they do not discharge any by products. Both the polyvinyl siloxane materials showed good linear dimensional stability.

According to the results obtained, NEXUS MEDODENT impression materials demonstrated better surface reproduction and in terms of linear dimensional stability when compared to BD IMPRESS impression material. Within 24 hours after preparation of the samples, both samples demonstrated almost equal values when evaluated under toolmaker microscope, but on the 7 th day there was a decrease in the values of BD impress, on the other hand NEXUS MEDODENT showed negligible changes in the values. On 14th day again BD IMPRESS showed a drastic change in their values when compared to 1st day, NEXUS MEDODENT has also shown decrease in their values but were less on comparison with BD impress.

Nassar et al investigated the surface detail reproduction and linear dimensional stability of a vinyl polyether silicone (VPES) in comparison to a vinylpolysiloxane (VPS) material as a function of prolonged storage for up to 2 weeks. The result was that the vinyl polyether siloxane experienced minimal dimensional changes when compared to vinyl polysiloxane, but the surface detail reproduction was not as consistent in vinyl polyether siloxane as compared to vinyl polysiloxane.[10] Similarly over a period of storage for 2 weeks the NEXUS MEDODENT impression was dimensionally stable when compared with BD IMPRESS impression material.

After analyzing the results obtained, it was found that linear linear dimensional stability was much better in NEXUS MEDODENT when compared to BD IMPRESS impression material.

\section{Conclusion}

According to the study conducted and results obtained, it was concluded that NEXUS MEDODENT was superior in linear dimensional stability on comparison with BD IMPRESS impression material. Along with the results it was found that BD IMPRESS was showing low thermal conductivity and more adhesiveness during manipulation which was found to be a drawback for this material.

There are few limitations for the present study and are as follows:

- The impressions were made from a metal die made according to ADA/ANSI specification no.19, which allowed only 2D measure- ment to assess the linear dimensional stability of the impression specimens and hence it does not mimic clinical conditions which includes the use of trays, adhesives for making impressions, presence of intraoral fluids and also the intraoral temperature would be also different.

- The study examined only the linear dimensional stability using impression specimens and compatibility of impression material with gypsum and the wettability of the materials with gypsum while pouring the impressions were not investigated in this study. - Finally, this study only examined the linear dimensional stability and accuracy of the BD IMPRESS with NEXUS MEDODENT. However, there is a need for further studies to examine the biological, rheological, wetting properties of this new material, and to provide additional support for clinical acceptance.

\section{References}

[1]. Sheta MS, El-Shorbagy ZA, Karim UM, Abd-Alla S. Laboratory comparative study of wettability, dimensional changes, flexibility and tear resistance of two recent elastomeric impression materials. Tanta Dental Journal. 2017 Apr 1;14(2):89.

[2]. Wadhwani CP, Johnson GH, Lepe X, Raigrodski AJ. Accuracy of newly formulated fast-setting elastomeric impression materials. J Prosthet Dent. 2005 Jun;93(6):530-9. PubmedPMID: 15942613.

[3]. Clancy JM, Scandrett FR, Ettinger RL. Long-term dimensional stability of three current elastomers. J Oral Rehabil. 1983 Jul;10(4):325-33. PubmedPMID: 6577158

[4]. Thomas W, Kumar P, Mathew S, Sarathchandran S, Jayanthi P. Effect of storage time and temperature change on the dimensional stability of polyvinyl siloxane and polyether impression materials: An in vitro study. Journal of Dr. NTR University of Health Sciences. 2016 Jul 1;5(3):204.

[5]. Revised American National Standard Institute/American Dental Association specification no. 19 for non-aqueous elastomeric dental impression materials.

[6]. Vadapalli SB, Atluri K, Putcha MS, Kondreddi S, Kumar NS, Tadi DP. Evaluation of surface detail reproduction, dimensional stability and gypsum compatibility of monophase polyvinyl-siloxane and polyether elastomeric impression materials under dry and moist conditions. J IntSocPrev Community Dent. 2016 Jul-Aug;6(4):302-8. PubmedPMID: 27583217.

[7]. Wassell RW, Abuasi HA. Laboratory assessment of impression accuracy by clinical simulation. J Dent. 1992 Apr;20(2):108-14. PubmedPMID: 1564180 .

[8]. Nassar U, Oko A, Adeeb S, El-Rich M, Flores-Mir C. An in vitro study on the dimensional stability of a vinyl polyether silicone impression material over a prolonged storage period. J Prosthet Dent. 2013 Mar;109(3):172-8. PubmedPMID: 23522366.

[9]. Rabeeba PK, Kataraki B, Bhavana BL, Rupesh PL, Basavaraj SS, Zainab N. Clinical Comparison of Quality of Vinyl Polyether Silicone Impressions with Polyvinyl Siloxane Impressions Using One-Step Impression Technique. Int. J. Curr. Adv. Res.2019;08(08):19691-6.

[10]. Gonçalves FS, Popoff DA, Castro CD, Silva GC, Magalhães CS, Moreira AN. Dimensional stability of elastomeric impression materials: a critical review of the literature. European Journal of Prosthodontics and Restorative Dentistry. 2011 Dec 1;19(4):163.

[11]. etrie CS, Walker MP, O'mahony AM, Spencer P. Dimensional accuracy and surface detail reproduction of two hydrophilic vinyl polysiloxane impression materials tested under dry, moist, and wet conditions. J Prosthet Dent. 2003 Oct;90(4):365-72. PubmedPMID: 14564291.

[12]. German MJ, Carrick TE, McCabe JF. Surface detail reproduction of elastomeric impression materials related to rheological properties. Dent Mater. 2008 Jul;24(7):951-6. PubmedPMID: 18164051.

[13]. Nagrath R, Lahori M, Agrawal M. A Comparative Evaluation of Dimensional Accuracy and Surface Detail Reproduction of Four Hydrophilic Vinyl Polysiloxane Impression Materials Tested Under Dry, Moist, and Wet Conditions-An In Vitro Study. J Indian Prosthodont Soc. 2014 Dec;14(Suppl 1):59-66. PubmedPMID: 26199493.

[14]. Aalaei S, RezaeiAdli A, Mansoorali MR, Gholami F. Dimensional stability of two polyvinyl siloxane impression materials in different time intervals. Journal of Dental Biomaterials. 2015 Nov 29;2(4):155-61.

[15]. Ragain JC, Grosko ML, Raj M, Ryan TN, Johnston WM. Detail reproduction, contact angles, and die hardness of elastomeric impression and gypsum die material combinations. Int J Prosthodont. 2000 May-Jun;13(3):214-20. Pubmed PMID: 11203635. 